\title{
Reversible platypnoea and orthodeoxia after surgical removal of an hydatid cyst from the liver
}

\author{
D. Patakas, G. Pitsiou, D. Philippou, D. Georgopoulos, E. Mavrofridis
}

\begin{abstract}
Reversible platypnoea and orthodeoxia after surgical removal of an hydatid cyst from the liver. D. Patakas, G. Pitsiou, D. Philippou, D. Georgopoulos, E. Mavrofridis. (C)ERS Journals Ltd 1999.

ABSTRACT: A patient with a large hydatid cyst of the liver developed a positionally symptomatic right to left shunting across a patent foramen ovale with both platypnoea and orthodeoxia, despite normal pulmonary arterial pressures and normal pulmonary function tests. When the patient was in the supine position the calculated right to left shunt was $15.1 \%$ and $29.5 \%$ when seated. The shunt was attributed to the compression of the right atrium and ventricle by the cyst. Surgical evacuation of the cyst relieved the symptoms and the positionally induced shunting.

Eur Respir J 1999; 14: 725-727.
\end{abstract}

Respiratory Failure Unit, University of Thessaloniki "G. Papanikolaou" Hospital, Thessaloniki, Greece.

Correspondence: D. Patakas, Respiratory Failure Unit, "G. Papanikolaou" Hospi- tal, Exohi, Thessaloniki, Greece. Fax: 3031350253

Keywords: Foramen ovale, hydatid cyst, orthodeoxia, platypnoea

Received: July 221998

Accepted after revision January 111999
Platypnoea, which is dyspnoea produced in the erect position and relieved in a recumbent one, and orthodeoxia, a worsening of arterial oxygen tension $\left(\mathrm{Pa}_{\mathrm{a}} \mathrm{O}_{2}\right)$ observed in association with platypnoea [1], have been reported to accompany pulmonary arteriovenous fistulae [2], severe chronic obstructive lung disease [1], adult respiratory distress syndrome [3], patent foramen ovale [4], hepato pulmonary syndrome [5] and to occur in patients after pneumonectomy [6-8].

In patients with chronic obstructive lung disease and adult respiratory distress syndrome, platypnoea and orthodeoxia are caused by a decrease in pulmonary blood flow in areas where alveolar pressure exceeds pulmonary artery pressure $[3,9]$. Post-pneumonectomy orthodeoxia is caused by a right to left intracardial shunt [6-8], and when arteriovenous fistulae are present in the lower lobes of the lungs, the right to left shunt can be increased by gravity while the patient is standing in the upright posture.

In this report, a patient is described with the abovementioned syndrome who developed a right to left shunt as a result of a large hydatid cyst of the liver, which had infiltrated the right diaphragmatic dome and compressed the right heart chambers.

\section{Case report}

A 54-yr-old male was admitted to the respiratory failure unit complaining of severe respiratory distress and cyanosis in the sitting posture which was further exaggerated in the standing position. The supine posture relieved these symptoms. He had 2 months of episodes of epigastric pain and paroxyisms of shortness of breath lasting a few minutes. The patient also noticed a low grade fever $\left(38^{\circ} \mathrm{C}\right)$ and loss of weight $(6-7 \mathrm{~kg})$. The painful episodes and the fever subsided a week before admission, but the breathlessness was aggravated.

On clinical examination heart sounds were normal, and no murmur was heard on repeated auscultations. The blood pressure of $135 / 75 \mathrm{mmHg}$ was unchanged by posture. An electrocardiogram was normal. Chest auscultation was unremarkable. The left liver lobe was palpable and tender. On radiography there was a visible elevation of the right diaphragmatic dome (fig. 1).
Further investigation showed normal spirometry: total lung capacity (TLC) $6.08 \mathrm{~L}$ (84\% predicted), vital capacity (VC) $3.75 \mathrm{~L}$ ( $8 \%$ pred) forced expiratory volume in one second (FEV1) $2.87 \mathrm{~L}$ (80\% pred), diffusing capacity of the lung for carbon monoxide (DL,CO) $30.0 \mathrm{~mL} \cdot \mathrm{min}^{-1}$ (98\% pred). On arterial blood gas analysis, severe hypoxaemia was noted, relieved by the supine position. The percentage venous to arterial shunt (QS/QT) calculated during breathing $100 \%$ oxygen and the physiological dead space $(V \mathrm{D} / V \mathrm{~T} \%)$ were increased in the upright position (table 1).

Catheterization of the right atrium and ventricle showed a mean right atrial pressure of $5 \mathrm{mmHg}$, a right ventricular pressure of $20 / 5 \mathrm{mmHg}$, a pulmonary artery pressure of $21 / 6$ $\mathrm{mmHg}$ (mean $11 \mathrm{mmHg}$ ), a pulmonary artery occlusion pressure of $5 \mathrm{mmHg}$, and a cardiac output of $5 \mathrm{~L} \cdot \mathrm{min}^{-1}$. Oxyhaemoglobin saturation was $59 \%$ in the right atrium and $60 \%$ in the pulmonary artery.

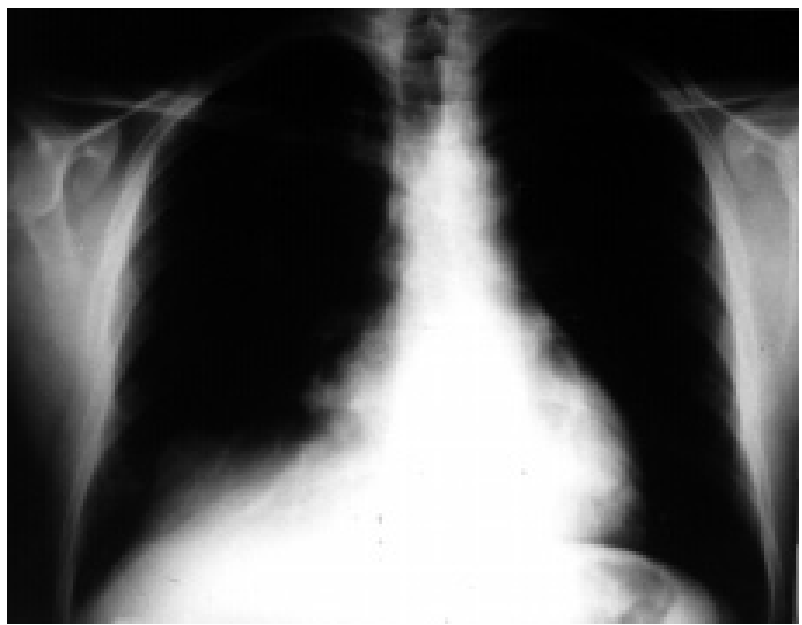

Fig. 1. - Radiograph showing elevation of the right diaphragmatic dome. 


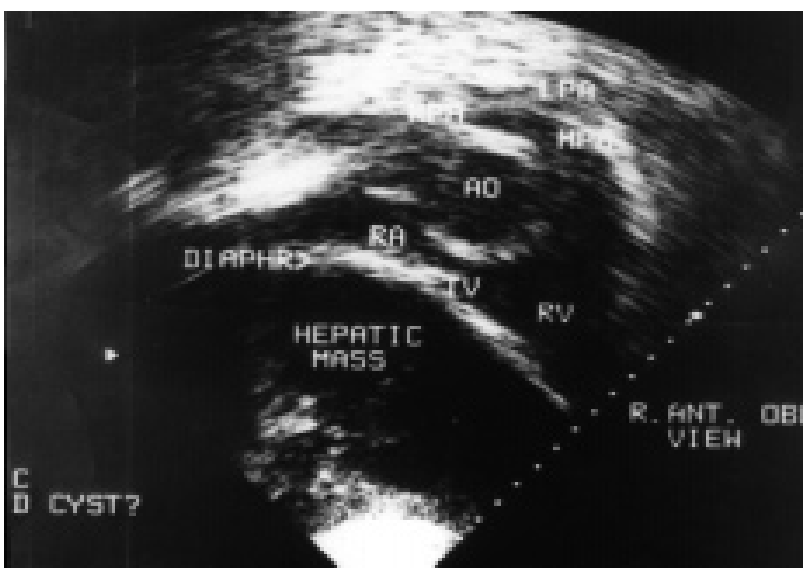

Fig. 2. - In the echocardiogram (right anterior oblique view) a large hepatic cyst can be seen elevating the diaphragm, compressing and deforming the right side chambers. RA: right atrium; TV: tricuspid value; RV: right ventricle; AO: aorta.

Ventilation-perfusion lung scans revealed a few scatter subsegmental areas of decreased ventilation and perfusion in the upper lobes compatible with emphysema.

In a two-dimensional echocardiogram, a large loculated hepatic cyst was observed compressing and deforming the right heart chambers (fig. 2). Injection of agitated saline into the antecubital vein showed right to left shunting across the interatrial septum. Computed tomography sections of the liver revealed a large hydatid cyst that occupied the left lobe of the liver and elevated the right hemidiaphragm, compressing the heart (fig. 3).

At surgery, a large hydatid cyst was found, peeled and drained; the adjacent hemidiaphragm and pericardium were infected.

Postoperatively, after recovery from anaesthesia, the arterial oxygen and carbon dioxide tensions improved in the supine position $\left(\mathrm{Pa}, \mathrm{O}_{2} 116 \mathrm{kPa}(87 \mathrm{mmHg}) ; \mathrm{Pa}_{2} \mathrm{CO}_{2} 4.8 \mathrm{kPa}(36\right.$ $\mathrm{mmHg})$ ) indicating an improvement in orthodeoxia, which was demonstrated after $48 \mathrm{~h}$ when the patient was able to assume the erect position (table 1). The shunt was calculated at $5.4 \%$ in the upright, and $4.8 \%$ in the supine positions.

\section{Discussion}

This report documents a 54-yr-old male, who had platypnoea and orthodeoxia caused by right to left shunting across a patent foramen ovale. A large hydatid cyst located in the left liver lobe had deformed and compressed the right sided heart chambers.

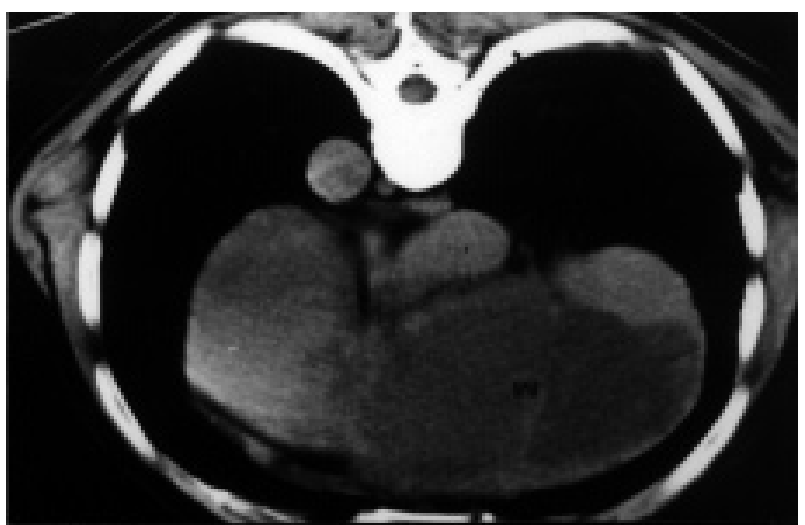

Fig. 3. - Axial contrast-enhanced computed tomographic scan. A liver mass $(\mathrm{M})$ can be seen to compress the heart.

Platypnoea and orthodeoxia are very unusual in patients with normal lung function; pulmonary disease and pulmonary hypertension enhance a tendency for right to left shunting across a patent foramen ovale [9]. The true incidence of patency of the foramen ovale is unknown, but autopsy studies have revealed an incidence of $27 \%$ in cases without associated heart disease with the opening diameter ranging in size from 1-19 $\mathrm{mm}^{2}$. Echo and Doppler imaging studies of normal subjects have revealed a prevalence of $7.5 \%$ patency of the foramen ovale during spontaneous breathing and of $15 \%$ during the Valsalva manoeuver [10].

Cardiac catheterization showed normal intracardiac pressures, and the mean right atrial pressure was equal to the pulmonary occlusion pressure (reflecting left atrial pressure). In the absence of a measurable interatrial pressure gradient, it was postulated that the shunt, which increased when the patient was in the upright position, was caused by a directed flow toward a patent foramen ovale. This directed flow was caused by an anatomical distortion of the right atrium as a result of pressure from the hydatid cyst. It is possible that the hydatid cyst changed the anatomic relationship of the inferior vena cava to the foramen ovale when the patient was in the upright position; this probably led to the significant right to left shunt. Previous studies have documented interatrial right to left shunt in the absence of a pressure gradient, suggesting directed flow from the right side of the heart into the left atrium [11].

One other case report [12] linked an interatrial shunt to a localized pericardial effusion; the patient also had a mean right atrial pressure equal to the pulmonary artery occlusion pressure, and the shunt resolved after medical therapy for the effusion. The pathophysiology of platypnoea and orthodeoxia of our patient is similar to this patient with pericarditis. Both cases related to right atrial compression and distortion

Table 1. - Serial arterial blood gas studies

\begin{tabular}{|c|c|c|c|c|c|c|c|c|c|c|}
\hline \multirow[b]{2}{*}{$F \mathrm{I}, \mathrm{O}_{2}$} & \multicolumn{2}{|c|}{$P a, \mathrm{O}_{2}$} & \multicolumn{2}{|c|}{$P \mathrm{a}, \mathrm{CO}_{2}$} & \multicolumn{2}{|c|}{$P \mathrm{~A}-\mathrm{a}, \mathrm{O}_{2}$} & \multicolumn{2}{|c|}{ QS/QT \% } & \multicolumn{2}{|c|}{$V \mathrm{D} / V \mathrm{~T} \%$} \\
\hline & Upright & Supine & Upright & Supine & Upright & Supine & Upright & Supine & Upright & Supine \\
\hline \multicolumn{11}{|l|}{ Preoperative } \\
\hline Room air & 33 & 71 & 31 & 23 & - & - & - & - & - & - \\
\hline $100 \%$ & 78 & 362 & 36 & 33 & 591 & 303 & 29.5 & 15.1 & 66 & 39 \\
\hline \multicolumn{11}{|l|}{ Postoperative } \\
\hline Room air & 95 & 90 & 40 & 37 & 9 & 10 & - & - & - & - \\
\hline $100 \%$ & 557 & 569 & 35 & 36 & 108 & 97 & 5.4 & 4.8 & 28 & 27 \\
\hline
\end{tabular}

Data presented as $\mathrm{mmHg}(1 \mathrm{mmHg}=0.133 \mathrm{kPa})$ except where indicated. $P \mathrm{a}, \mathrm{O}_{2}$ : arterial oxygen tension; $P \mathrm{a}, \mathrm{CO}_{2}$ : arterial carbon dioxide tension; $P \mathrm{~A}-\mathrm{a}, \mathrm{O}_{2}$ : alveolar-arterial pressure difference for oxygen; QS/QT: percentage venous to arterial shunt; $V \mathrm{D} / V \mathrm{~T}$ : physiological dead space; $F \mathrm{I}_{1} \mathrm{O}_{2}$ : inspiratory oxygen fraction (flow $6 \mathrm{~L} \cdot \mathrm{min}^{-1}$ ). 
resulting in a right to left shunt. These reports emphasize the effectiveness of management of right to left shunting through a patent foramen ovale by medical or, in the present case, surgical procedures aimed to decompress the right side heart chambers.

\section{References}

1. Altman M, Robin ED. Platypnea (diffuse zone I phenomenon?). N Engl J Med 1969; 281: 1347-1348.

2. Robin ED, Loman D, Horn BR, Theodore J. Platypnea related to orthodeoxia caused by true vascular lung shunt. $N$ Engl J Med 1976; 294: 941-943.

3. Khan F, Pareck A. Reversible platypnea and orthodeoxia following recovery from adult respiratory distress syndrome. Chest 1979; 75: 526-528.

4. Sorrentino M, Resnekov L. Patent foramen ovale associated with platypnea and orthodeoxia. Chest 1991; 100: 1157-1158.

5. Hervé $\mathrm{P}$, Lebrec $\mathrm{D}$, Brenot $\mathrm{F}$, et al. Pulmonary vascular disorders in postal hypertension. Eur Respir J 1998; 11: $1153-1166$.
6. LaBresh KA, Pietro DA, Coates EO, et al. Platypnea syndrome after pneumonectomy. Chest 1981; 79: 605-607.

7. Franco DP, Kinasewitz GT, Markham RV, Tucker WV, George RB. Postural hypoxemia in the postpneumonectomy patient. Am Rev Respir Dis 1984; 129: 1021-1022.

8. Smeenk F, Postmus P. Interatrial right to left shunting developing after pulmonary resection in the absence of elevated right-sided heart pressures. Chest 1993; 103: 528-531.

9. Seward JB, Hayes DL, Smith HC, et al. Platypnea-orthodeoxia: clinical profile, diagnostic workup, management and report of seven cases. Mayo Clin Proc 1984; 59: 221-231.

10. Webster MWI, Chancellor AM, Smith IIJ, et al. Patent foramen ovale in young stroke patients. Lancet 1988; 2: 11-12.

11. Strunk BL, Cheithin MD, Stulbarg MS, Schiller NB. Right to left interatrial shunting through a patent foramen ovale despite normal intracardiac pressures. Am J Cardiol 1987; 60: 413-415.

12. Adolph E, Lacy W, Hermoni Y, Wexler L, Javakeri S. Reversible orthodeoxia and platypnea due to right to left intracardiac shunting related to pericardial effusion. Ann Intern Med 1992; 116: 138-139. 